
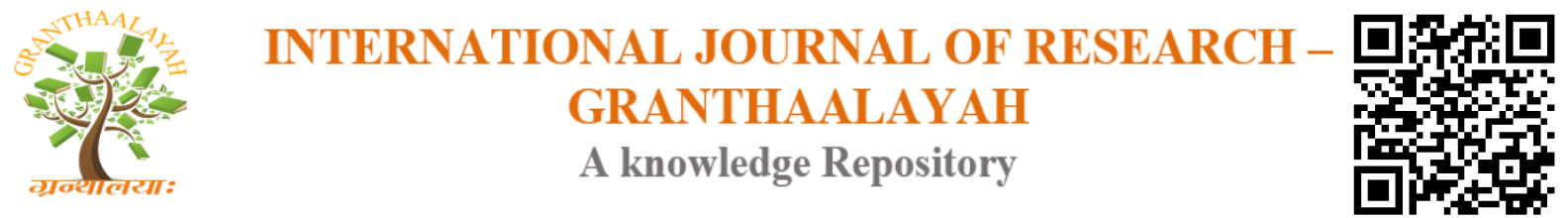

Science

\title{
CEPHALOMETRIC NORMS FOR GUJARATI CHILDREN - A CROSS SECTIONAL STUDY
}

\author{
Dr. Purva B Butala ${ }^{1}$, Dr. Purv S Patel ${ }^{2}$, Dr. M Ganesh ${ }^{3}$ \\ ${ }^{1}$ Reader, Pedodontics and Preventive Dentistry Department, Ahmedabad Dental College \& \\ Hospital, India \\ ${ }^{2}$ Reader, Oral Medicine and Radiology Department, Ahmedabad Dental College and Hospital, \\ India \\ ${ }^{3}$ Professor \& Head, Pedodontics and Preventive Dentistry Department, Ahmedabad Dental \\ College and Hospital, India
}

\begin{abstract}
Introduction: Orthodontists have relied on cephalometric radiographs for orthodontic diagnosis and treatment planning since the advent of cephalometric radiography. The variations in different ethnic groups within the same country creates a need for cephalometric norms for each of such ethnic groups. McNamara's analysis is the most commonly used and most suitable for diagnosis and treatment planning.

Aim: The study aims to formulate cephalometric norms for Gujarati boys and girls using McNamara's analysis.

Materials \& Method: The sample of children for the study was selected from the government funded primary schools of Gujarat. The sample size consisted of 250 school going Gujarati children (125 boys and 125 girls) with age ranging from 9 to 12 years.

Materials \& Method: A digital lateral cephalograph was taken under standard conditions for all children and manual tracings were done for identifying all cephalometric landmarks. The analysis was done using McNamara's analysis and statistical analysis was done

Statistical Analysis: Gender differences were calculated using student's t test. The software was utilized to calculate the mean value, standard deviation, range, maximum and minimum values for all parameters of McNamara's analysis for Gujarati boys as well as girls. The inter examiner variability was tested using Karl Pearson correlation test.

Results: The mean and standard deviation with minimum values, maximum values and range for each of 11 parameters were calculated for all male and female subjects. The gender differences were also calculated for all subjects.

Conclusion: This study introduces cephalometric norms for the mixed dentition period using McNamara Analysis for Gujarati children residing in Ahmedabad - Gandhinagar districts of Gujarat which can be utilized for orthodontic treatment in the future.
\end{abstract}

Keywords: Cephalometric Norms; Gujarati Children; Mcnamara’s Analysis. 
Cite This Article: Dr. Purva B Butala, Dr. Purv S Patel, and Dr. M Ganesh. (2020). "CEPHALOMETRIC NORMS FOR GUJARATI CHILDREN - A CROSS SECTIONAL STUDY." International Journal of Research - Granthaalayah, 8(4), 313-326. https://doi.org/10.29121/granthaalayah.v8.i4.2020.42.

\section{Introduction}

Beauty of face is an ill-defined concept that is obvious to observer and recognized crossculturally. ${ }^{1}$ Throughout recorded history and even earlier, human beings have been aware of and concerned about beauty and facial esthetics. ${ }^{2,3}$ Orthodontics is a combination of art and science and facial esthetics is the reflection of the orthodontist's artistic intuition. ${ }^{4}$ An esthetically pleasing smile is a key determinant of successful orthodontic treatment and patient satisfaction. ${ }^{2,4}$ It is generally accepted that growth of various parts of the body neither proceeds at the same rate nor follows the same patterns. Orthodontists and pedodontists are interested in understanding how the face changes from its embryologic form through childhood, adolescence and adulthood. If we had a better understanding of relationships among different parts of the developing skeleton, it would be possible to make more-informed decisions about the timing and type of interventions. ${ }^{5}$ During the deciduous dentition phase, some malocclusions are already evident and they show a distinctive craniofacial pattern. Many authors have recommended an early orthodontic/orthopedic approach to different types of malocclusion. ${ }^{6}$ The craniofacial features, both skeletal and dental are either of genetic origin, nutritionally acquired or are specific to some ethnic, racial, sub-racial as well different community groups. ${ }^{5,7-9}$ Consequently, cephalometric standards were gradually established for different racial and ethnic groups and it was indeed found that there was no universal cephalometric standard; but that cephalometric norms differ for different ethnic groups. ${ }^{1,10-12}$

Cephalometry means "head measuring" and cephalometric analysis is the study of dental and skeletal relationships to the head. ${ }^{13}$ Since the advent of cephalometric radiography by Broadbent \& Hofrath (1931), orthodontists focused on the lateral cephalograms as their primary source of skeletal and dentoalveolar data. ${ }^{14-17}$ Cephalometric analysis is a useful diagnostic tool to determine facial type and its growth pattern, in order to centralize therapeutic measures during treatment and modify facial growth in children and adolescents. ${ }^{4,8,10,18,19}$ Many different systems for analysis have been suggested, which can grossly be classified into two groups. Some evaluate the patient with regard to specific standards, which are also used to set the treatment goal, e.g. the analysis described by Tweed $(1954)^{20}$, Steiner $(1960)^{21}$ and Ricketts (1961). ${ }^{22}$ Other analyses are performed with the purpose of understanding the malocclusion, whether it is of dentoalveolar or skeletal origin, e.g. those described by Bjork [1947] ${ }^{23}$, Downs [1948] $]^{24}$, Enlow [1971] ${ }^{25}$ and McNamara $[1984]{ }^{10,26}$ They are based on factors such as age, sex, size and race. ${ }^{14}$

The planning of orthodontic treatment often includes comparison of craniofacial structure of a patient to the norm. ${ }^{27}$ It is always preferable to compare the cephalometric values of the patient to the norm of their ethnic or racial group. The cephalometric analysis can then be used to accurately identify the deviation found in the patient. ${ }^{7,8,11,16}$ Cephalometric norms have been established using various analyses for the Indian population like for the North Indians, \& Maharashtrians, Bunts, Gurkhas, Madras city population, Aryo-Dravidians, North Indian preschool children, South Kanara Children, South Indians and Indo-Aryans but for the Gujarati population, norms were 
established only for Gujarati adolescent girls. ${ }^{28}$ Thus, developing cephalometric norms for the Gujarati child population in the mixed dentition period may prove useful.

McNamara's analysis is the most suitable for diagnosis, treatment planning and treatment evaluation, not only of conventional orthodontic patients, but also for patients with skeletal discrepancies who require orthognathic surgery. ${ }^{15}$ Hence, McNamara's cephalometric analysis was utilized in this study to establish the new cephalometric norms for Gujarati boys and girls in the mixed dentition period since there are no existing norms for this population.

\section{Methods}

- A cross-sectional radiographic study was conducted in the Department of Pedodontics and Preventive Dentistry of the institute. The ethical approval for the study was obtained from the Ethical Committee of the institute.

\section{Source of Data and Selection Of Subjects}

- The sample of children for the study was selected from the government funded primary schools of Ahmedabad and Gandhinagar districts of Gujarat. The sample size consisted of 1500 school going Gujarati children ( 750 boys and 750 girls) with age ranging from 9 to 15 years.

- All the subjects were clinically examined and only those with Angle's Class I occlusion with adequate lip seal and age ranging from $9-15$ years were included in the study. Subjects who were non Gujarati in origin, having any malocclusion, facial asymmetry, history of oral destructive habits, orthodontic treatment or any systemic disease or growth disorder were excluded from the study.

\section{Method}

- The subjects for the study were examined using the diagnostic armamentarium [Figure 1] with prior permission of the respective school principal and selected by multiphase sampling according to the inclusion criteria and exclusion criteria.

- Patients selected for the study were explained the entire procedure with its associated risks, along with their parent(s)/guardian(s), with the help of an information sheet. After obtaining a signature/thumb impression on the informed consent form from the parent/guardian, finally 1500 children were included in the study.

- Information regarding the name and age of the subject as well as birth place and mother tongue of the subject and his/her parents was obtained from the school to which the subject belonged. All the demographic details of the subjects were recorded in the proforma specially prepared for the study. Each subject was then assigned a subject ID based on their order of inclusion in the study. They were subjected to radiographic examination.

\section{Lateral Cephalometric Radiographic Examination}

- The median plane of the subject was marked with barium sulphate solution. The subject was made to wear lead apron and thyroid collar to minimize radiation exposure. The subject was then positioned in the cephalostat [Figure $2 \& 3(\mathrm{a}, \mathrm{b})$ ] and made to look into a mirror at a distance of 7 feet in front of the patient in a comfortable position of natural balance as per the method of Moorrees and Kean (1958). ${ }^{29}$ The subject was instructed to bring his/her teeth in maximum intercuspation and lips in light contact. Ear rods were placed in position and subject was instructed to remain steady. Then cephalogram was taken under standard conditions with the distance from focus to the median plane of the patient's head of 5 feet and exposure parameters of $81 \mathrm{kVp}, 10 \mathrm{~mA} \& 14.6$ seconds. [Figure 4] The cephalometric 
radiographs of all patients were taken in the same machine. Each cephalogram was then printed in a Kodak printer.

\section{Cephalometric Analysis}

- Each printed cephalograph was attached with a polyester acetate tracing paper, then placed on a viewing box and the following traditional cephalometric points and contours were marked using a 3H pencil [Figure 5]; nasion, ANS, point A, pogonion, menton, gnathion, gonion, orbitale, porion, condylion, sella, basion and ptm (pterygomaxillary fissure) point. Cephalometric analysis was done based on McNamara's method for skeletal and dental variables as shown below.

\begin{tabular}{|c|c|c|c|}
\hline \multicolumn{4}{|c|}{ Landmarks and References Lines for McNamara Analysis } \\
\hline \multicolumn{4}{|c|}{ Maxilla to cranial base } \\
\hline 1 & $\begin{array}{l}\text { NA-P } \\
\text { perpendicular }\end{array}$ & $\begin{array}{l}\text { Nasion perpendicular } \\
\text { to point } A\end{array}$ & $\begin{array}{l}\text { A vertical line is constructed perpendicular to the } \\
\text { Frankfort horizontal and extended inferiorly from } \\
\text { the nasion. The perpendicular distance is } \\
\text { measured from point A to the nasion } \\
\text { perpendicular }\end{array}$ \\
\hline 2 & SNA & & The angle between the SN and NA lines \\
\hline \multicolumn{4}{|c|}{ Mandible to Maxilla } \\
\hline 3 & $\mathrm{Co}-\mathrm{Gn}$ & $\begin{array}{l}\text { Effective mandibular } \\
\text { length }\end{array}$ & $\begin{array}{l}\text { A line is measured from the condylion to the } \\
\text { anatomic gnathion }\end{array}$ \\
\hline 4 & $\mathrm{Co}-\mathrm{A}$ & $\begin{array}{l}\text { Effective midface } \\
\text { length }\end{array}$ & A line is measured from the condylion to point $\mathrm{A}$ \\
\hline 5 & Mx MD - DF & $\begin{array}{l}\text { Maxillomandibular } \\
\text { differences }\end{array}$ & $\begin{array}{l}\text { Effective mandibular length minus effective } \\
\text { midface length }\end{array}$ \\
\hline 6 & ANS - Me & $\begin{array}{l}\text { Lower anterior face } \\
\text { height }\end{array}$ & $\begin{array}{l}\text { A line measured from the anterior nasal spine to } \\
\text { the menton }\end{array}$ \\
\hline 7 & $\mathrm{MD}-\mathrm{P}$ & $\begin{array}{l}\text { Mandibular plane } \\
\text { angle }\end{array}$ & $\begin{array}{l}\text { The angle between the anatomic Frankfort plane } \\
\text { and the mandibular plane, gonion - menton }\end{array}$ \\
\hline 8 & $\mathrm{FA}-\mathrm{A}$ & Facial axis angle & $\begin{array}{l}\text { A line is conducted from the } \\
\text { basion to the nasion (NBa). A second line (the } \\
\text { facial axis) is constructed gnathion (the } \\
\text { intersection of the facial plane and the mandibular } \\
\text { plane). The facial axis angle is the angle between } \\
\text { the NBa and the facial axis. }\end{array}$ \\
\hline \multicolumn{4}{|c|}{ Mandible to Cranial base } \\
\hline 9 & $\mathrm{Pg}-\mathrm{N}$ & $\begin{array}{l}\text { Pogonion to nasion } \\
\text { perpendicular }\end{array}$ & $\begin{array}{l}\text { The perpendicular distance is measured from the } \\
\text { pogonion to the nasion perpendicular. }\end{array}$ \\
\hline \multicolumn{4}{|c|}{ Dentition } \\
\hline 10 & $\mathrm{Ui}-\mathrm{A}$ & $\begin{array}{l}\text { Upper incisor to point } \\
\text { A }\end{array}$ & $\begin{array}{l}\text { A point A perpendicular is constructed parallel to } \\
\text { the nasion perpendicular through point A. The } \\
\text { perpendicular distance is measured from the most } \\
\text { anterior surface of the upper incisor to the point } \\
\text { A perpendicular. }\end{array}$ \\
\hline 11 & $\mathrm{Li}-\mathrm{APg}$ & $\begin{array}{l}\text { Lower incisor to } \mathrm{A}- \\
\text { Po line }\end{array}$ & $\begin{array}{l}\text { The distance is measured from the facial surface } \\
\text { of the lower incisor to the A pogonion line. }\end{array}$ \\
\hline
\end{tabular}


- For the bilateral structures that cast double shadows on the radiograph, the midpoint of the two shadows on the radiograph was considered the cephalometric point required for the study. All the tracings were made by the same person to avoid inter examiner variation. Inter examiner reliability was checked for the measurements of the various parameters.

\section{Statistical Analysis}

- SPSS (Statistical Package for Social Sciences) 22.0 for Windows (SPSS, Inc., Chicago, IL) was used for all analysis.

- The software was utilized to calculate the mean value and standard deviation for all parameters of McNamara's analysis for Gujarati boys as well as girls.

- The gender differences were statistically tested using independent $t$ - test. In all these tests, $\mathrm{p}>0.05$ indicated no statistical difference while $\mathrm{p} \leq 0.05$ indicated statistically significant difference between the measurement of boys and girls for that respective parameter.

- The interexaminer variability was tested using Karl Pearson correlation test. The relation was considered a perfectly positive correlation for all the parameters having $p \leq 0.005$ while $\mathrm{p}>0.005$ indicated a negative correlation between the two examiners for that respective parameter.

- Reproducibility of points and measurement of reliability was done by tracing and measurement of 100 radiographs after 3 weeks using Nemotech software, the difference between the first and second measurement was found to be statistically insignificant using ICC (intraclass correlation coefficient) test.

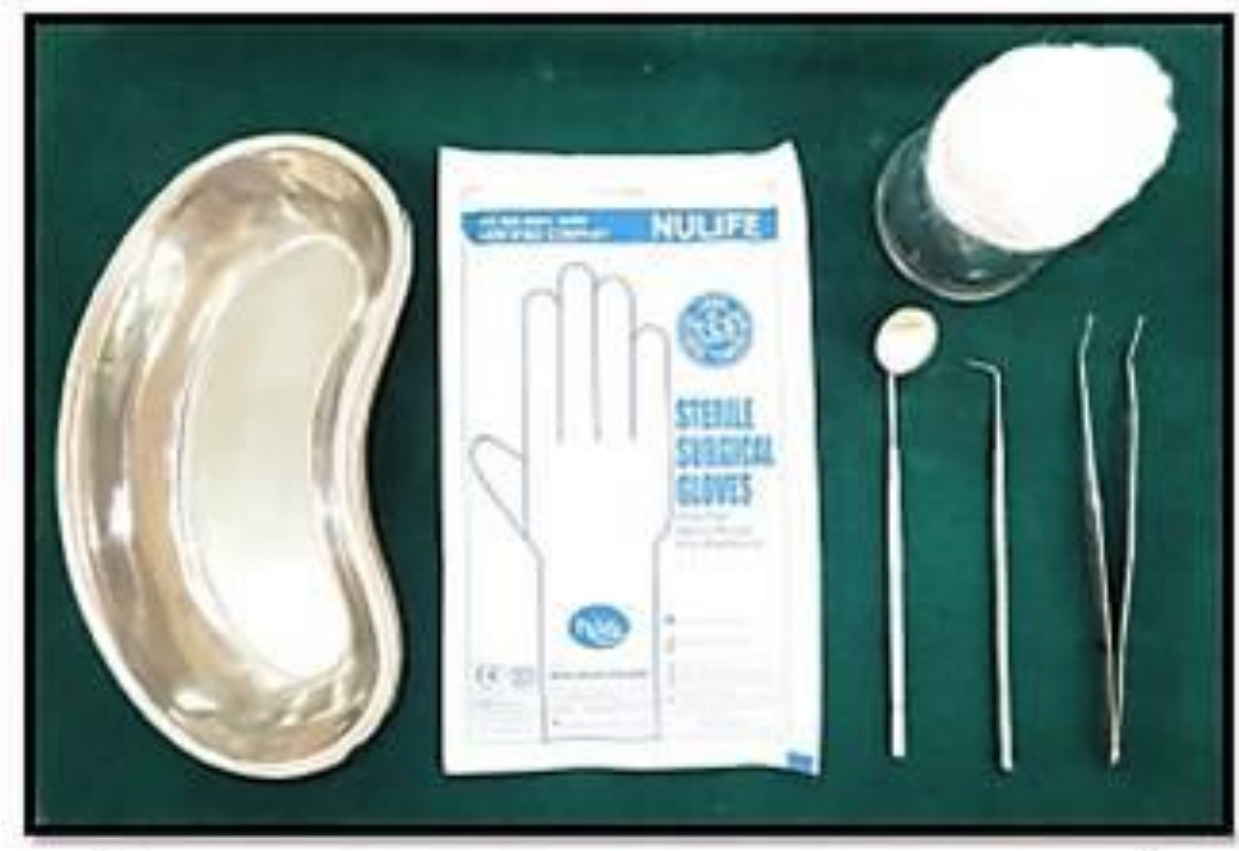

Figure 1: Diaguostic Armamentarium 


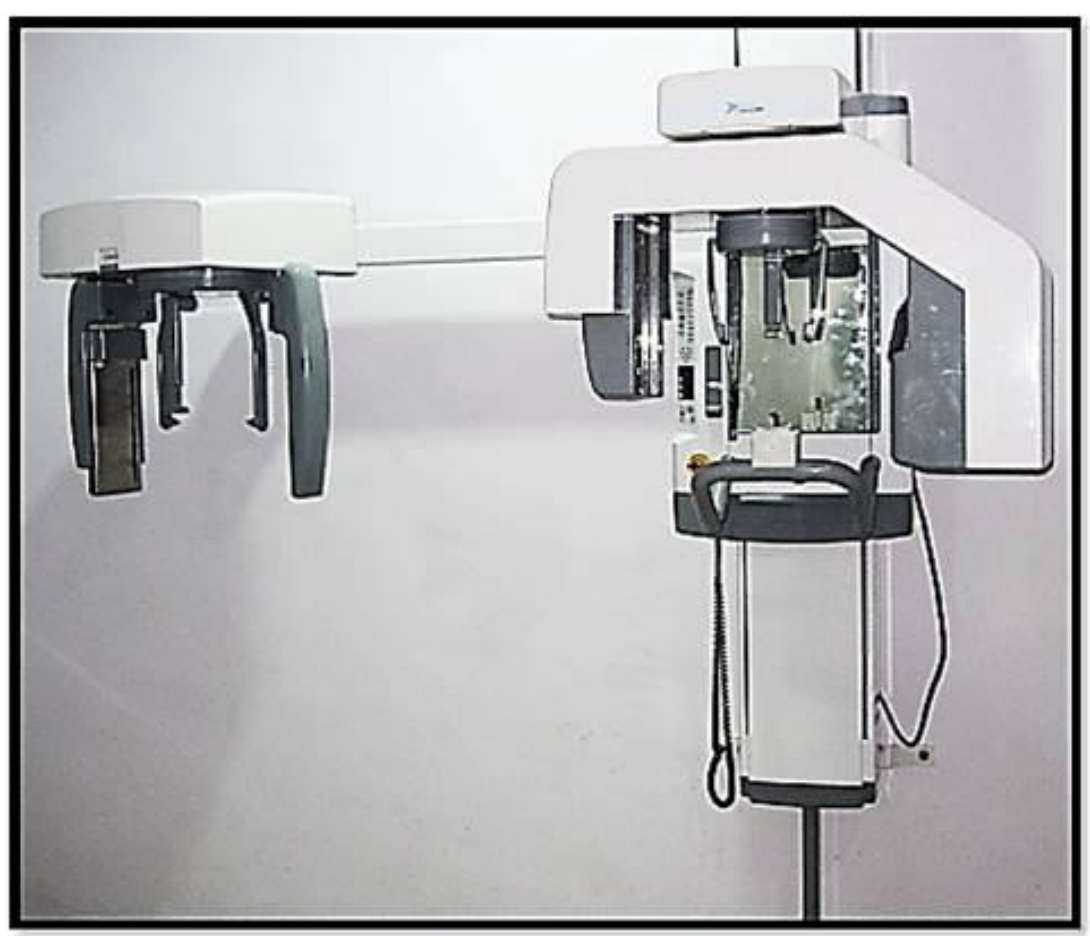

Figure 2: Photograph showing OPG machine with Cephalostat

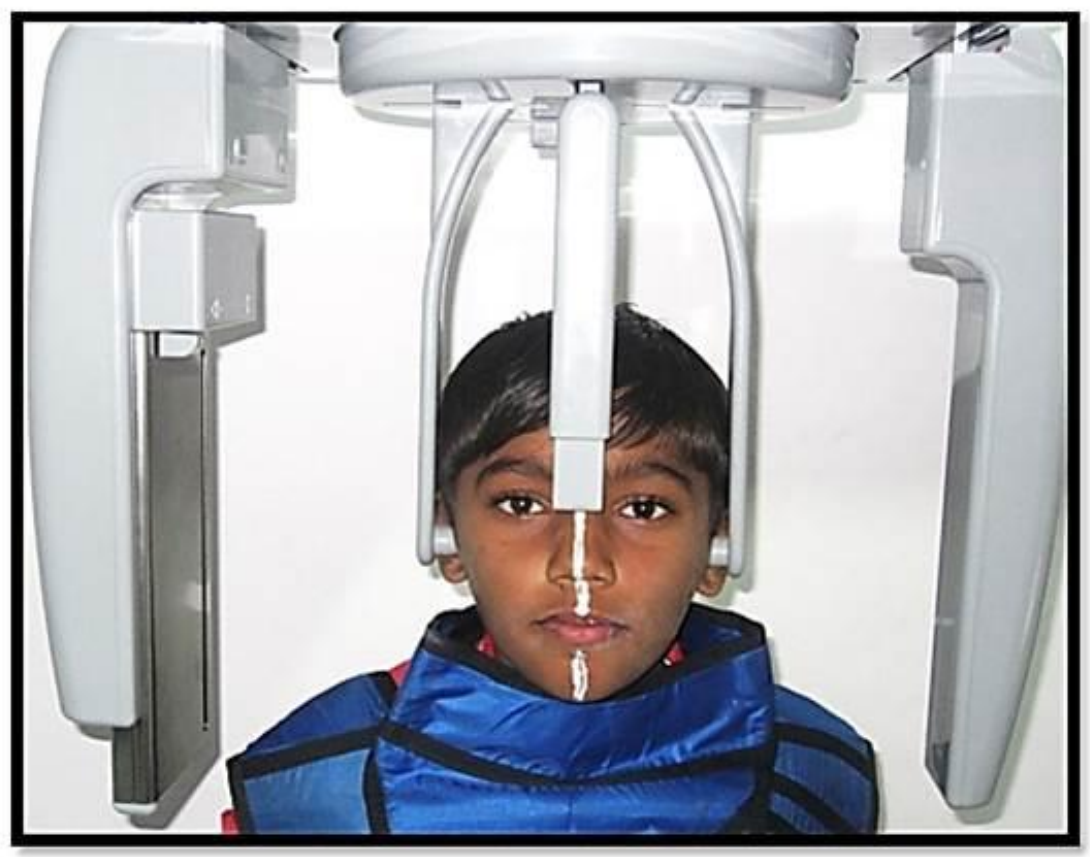

Figure 3a: Front view of subject positioned in cephalostat 


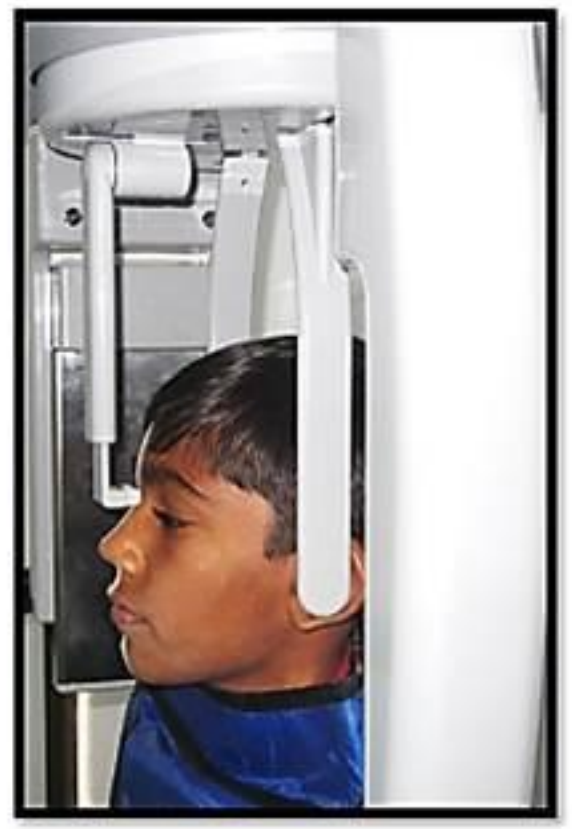

Figure 3b: Profile view of subject positioned in cephalostat

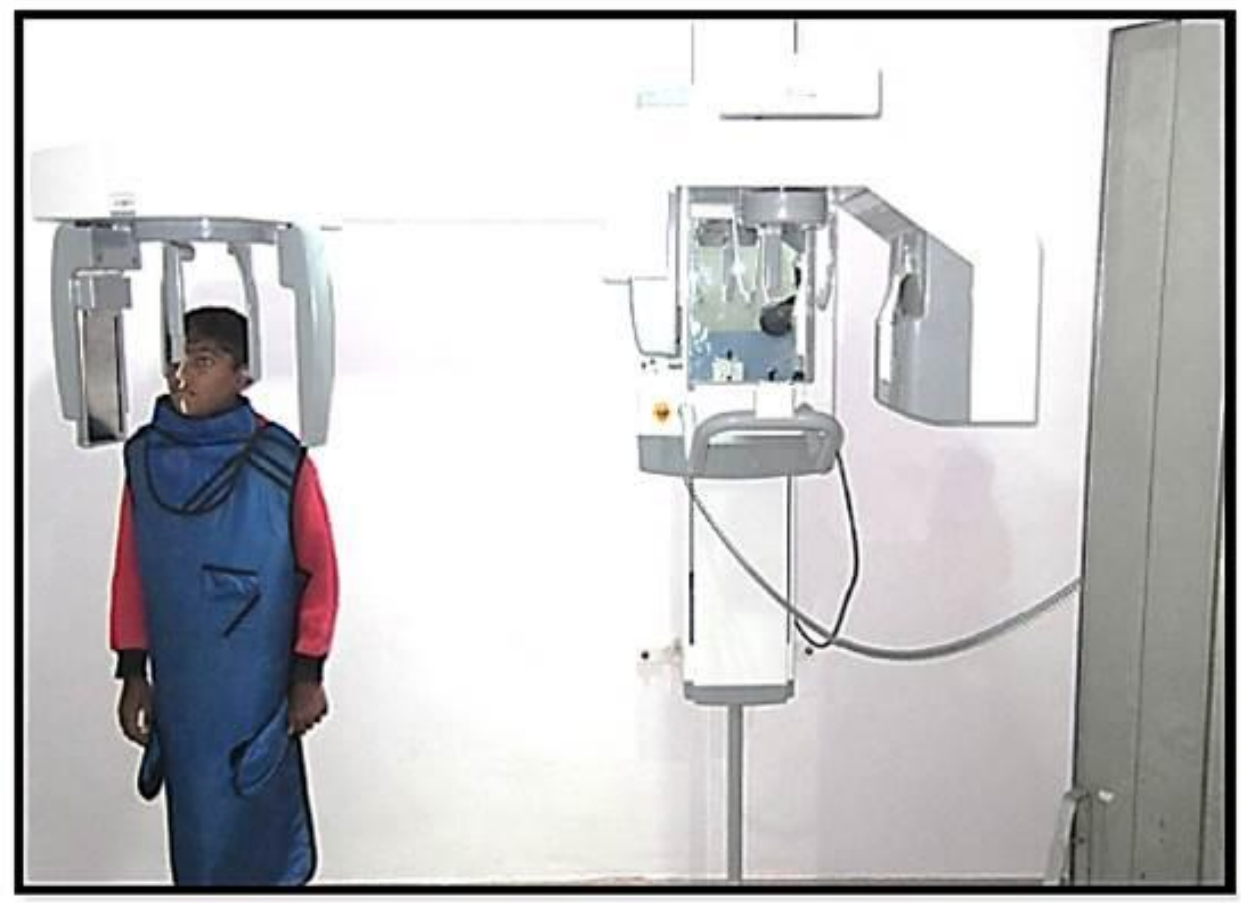

Figure 4: Photograph of subject while taking lateral cephalometric radiograph 


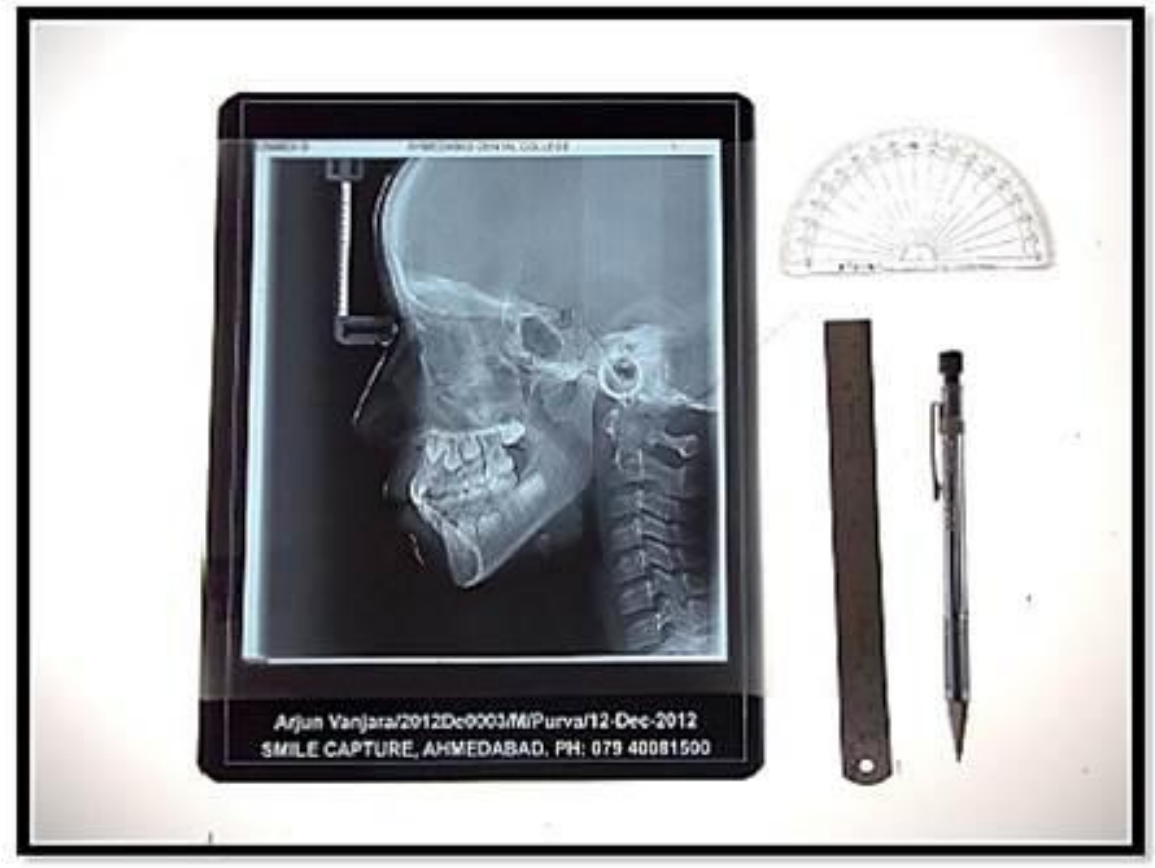

Figure 5: Tracing armamentarium with traced cephalometric radiograph

\section{Results}

The study consisted of 1500 subjects amongst which 750 were males and 750 were females. The mean age was 13.73 years amongst males and 12.89 years amongst females as shown by Table 1.

Table 1: Gender Wise Distribution of The Study Sample with Their Mean Age

\begin{tabular}{|l|c|c|}
\hline & Number of subjects (N) & Mean Age \\
\hline Male & 750 & 13.73 \\
\hline Female & 750 & 12.89 \\
\hline Total & 1500 & \\
\hline
\end{tabular}

The mean and standard deviation (S. D.) for each of 11 parameters for male and female subjects are shown in Table 2.

Table 2: Cephalometric Norms of Mcnamara Analysis For Gujarati Boys \& Girls

\begin{tabular}{|l|c|c|c|c|c|c|}
\hline \multirow{2}{*}{} & \multicolumn{3}{|c|}{ BOYS } & \multicolumn{3}{c|}{ GIRLS } \\
\cline { 2 - 7 } & $\mathbf{N}$ & Mean & Standard deviation & N & Mean & Standard deviation \\
\hline $\mathrm{Na}-\mathrm{P}$ & 750 & -0.569 & 3.564 & 750 & 0.182 & 3.574 \\
\hline SNA & 750 & 84.784 & 3.122 & 750 & 84.259 & 4.692 \\
\hline Pog - NP & 750 & -5.667 & 5.478 & 750 & -4.892 & 5.923 \\
\hline $\mathrm{Co}-\mathrm{Gn}$ & 750 & 94.678 & 10.332 & 750 & 93.435 & 4.320 \\
\hline $\mathrm{Co}-\mathrm{A}$ & 750 & 78.908 & 4.632 & 750 & 77.432 & 3.459 \\
\hline $\mathrm{Mx}-\mathrm{MD}-\mathrm{DF}$ & 750 & 21.453 & 3.009 & 750 & 20.632 & 3.692 \\
\hline
\end{tabular}




\begin{tabular}{|l|c|c|c|c|c|c|}
\hline ANS - Me & 750 & 55.897 & 3.744 & 750 & 54.409 & 3.287 \\
\hline MD - P & 750 & 24.832 & 4.903 & 750 & 24.398 & 5.643 \\
\hline FA - Axis & 750 & 2.459 & 3.659 & 750 & 2.702 & 4.654 \\
\hline Ui - A & 750 & 3.564 & 2.538 & 750 & 4.290 & 1.780 \\
\hline $\mathrm{Li}-\mathrm{A}-\mathrm{Pog}$ & 750 & 3.334 & 1.998 & 750 & 3.025 & 1.853 \\
\hline
\end{tabular}

The gender wise differences in the measurements of the parameters of McNamara's analysis are shown in Table 3.

Table 3: Comparison of Cephalometric Norms Between Gujarati Boys \& Girls

\begin{tabular}{|l|c|c|c|c|}
\hline & Mean value for boys & Mean value for girls & Mean Difference & P value \\
\hline $\mathrm{Na}-\mathrm{P}$ & -0.569 & 0.182 & -0.387 & 0.320 \\
\hline $\mathrm{SNA}$ & 84.784 & 84.259 & 0.525 & 0.743 \\
\hline $\mathrm{Pog}-\mathrm{NP}$ & -5.667 & -4.892 & -0.775 & 0.252 \\
\hline $\mathrm{Co}-\mathrm{Gn}$ & 94.678 & 93.435 & 1.243 & 0.789 \\
\hline $\mathrm{Co}-\mathrm{A}$ & 78.908 & 77.432 & 1.476 & 0.094 \\
\hline $\mathrm{Mx}-\mathrm{MD}-\mathrm{DF}$ & 21.453 & 20.632 & 0.821 & 0.738 \\
\hline $\mathrm{ANS}-\mathrm{Me}$ & 55.897 & 54.409 & 1.488 & $0.023^{*}$ \\
\hline $\mathrm{MD}-\mathrm{P}$ & 24.832 & 24.398 & 0.434 & 0.456 \\
\hline $\mathrm{FA}-\mathrm{Axis}$ & 2.459 & 2.702 & -0.243 & 0.743 \\
\hline $\mathrm{Ui}-\mathrm{A}$ & 3.564 & 4.290 & -0.726 & 0.572 \\
\hline $\mathrm{Li}-\mathrm{A}-\mathrm{Pog}$ & 3.334 & 3.025 & 0.309 & 0.971 \\
\hline$* \mathrm{p}$ value $<0.05=$ statistical significant difference & & \\
\hline
\end{tabular}

The correlation coefficient values of the measurements of the parameters by the two observers are mentioned in Table 4.

Table 4: Inter examiner Differences for Cephalometric Norms of Mcnamara Analysis

\begin{tabular}{|l|c|c|c|}
\hline & $\mathbf{N}$ & Correlation & P value \\
\hline $\mathrm{Na}-\mathrm{P}$ & 100 & 0.998 & $<0.0001$ \\
\hline $\mathrm{SNA}$ & 100 & 0.931 & $<0.0001$ \\
\hline $\mathrm{Pog}-\mathrm{NP}$ & 100 & 0.912 & $<0.0001$ \\
\hline $\mathrm{Co}-\mathrm{Gn}$ & 100 & 0.979 & $<0.0001$ \\
\hline $\mathrm{Co}-\mathrm{A}$ & 100 & 0.934 & $<0.0001$ \\
\hline $\mathrm{Mx}-\mathrm{MD}-\mathrm{DF}$ & 100 & 0.940 & $<0.0001$ \\
\hline $\mathrm{ANS}-\mathrm{Me}$ & 100 & 0.925 & $<0.0001$ \\
\hline $\mathrm{MD}-\mathrm{P}$ & 100 & 0.959 & $<0.0001$ \\
\hline $\mathrm{FA}-\mathrm{Axis}$ & 100 & 0.422 & 0.005 \\
\hline $\mathrm{Ui}-\mathrm{A}$ & 100 & 0.977 & $<0.0001$ \\
\hline $\mathrm{Li}-\mathrm{A}-\mathrm{Pog}$ & 100 & 0.998 & $<0.0001$ \\
\hline
\end{tabular}

\section{Discussion}

Clinical pedodontics and orthodontics have seen the advent of numerous preventive as well as interceptive procedures, which allow three dimensional repositioning of almost every bony 
structure in the facial region and of functional appliance therapy which presents new possibilities in the treatment of skeletal discrepancies. ${ }^{8,11,16,30-32}$ Cephalometric analysis is the most commonly used method to assess the dentofacial morphology, which is important in orthodontic treatment planning and evaluation of treatment changes. ${ }^{32}$ The shape and size of the craniofacial complex changes with age, so does the values of cephalometric measurements. Hence, cephalometric standards should be available for different age groups. ${ }^{33}$ Most of the cephalometric analyses which are used today in India have originated in White North American adults. Most importantly, in a country like India where the intracountry variation in population is found to a great extent morphogenetically as well as linguistically, developing a specific normative standard for the entire population can be erroneous in nature. Therefore, existence of norms based on individual population groups becomes an absolute necessity to produce acceptable results. ${ }^{9,12,18,30,33}$ Kotak $(1964)^{34}$ conducted a study of adolescent Gujarati girls and derived cephalometric variables based on Down's analysis. However, no cephalometric norms exist for the Gujarati preadolescent population. Hence, this study was undertaken with the aim to establish cephalometric norms for the Gujarati children.

Orthodontic treatment in the early mixed and even in the late deciduous dentition has been indicated for several reasons. ${ }^{35}$ Traditionally, the emphasis has been on periods of maximum growth changes, i.e. the adolescent years. ${ }^{5}$ Skeletal discrepancies show better results when treated during growth period. ${ }^{8}$ Most patients undergo orthodontic treatment at around 10-14 years of age, and priority should be given to obtaining solid norms for this age group. ${ }^{15}$ Hence, relative cephalometric normative standards for young individuals are essential in the diagnosis of and treatment planning for these age groups. ${ }^{35}$ Considering this fact, the study was conducted on individuals ranging from 9 to 12 years age in the mixed dentition period.

Numerous studies have shown intrapopulation gender based differences for various linear and angular cephalometric measurements between males and females. ${ }^{10-12,33,35,36}$ For McNamara analysis, there was a statistically significant difference between males and females in about half of variables. ${ }^{32,37}$ Therefore, cephalometric standards should be available for different gender groups to be used for orthodontic and other diagnosis, and treatment planning. ${ }^{35}$ In accordance with these findings, the measurements of male and female subjects were analyzed for statistically significant differences. Reduction of selection bias is of primary importance when norms for populations are to be established. ${ }^{27}$ In order to overcome this bias, the sample was selected from the randomly chosen primary schools. The norms are usually derived from samples demonstrating ideal dental occlusions of the class I variety. ${ }^{38}$ Various population norms have been obtained from a random sample of subjects with Class I occlusion including those with minor malocclusions. ${ }^{32}$ Hence, the subjects having Angle's class I occlusion with normal overjet and overbite were selected for the study. Ethnic homogeneity was achieved by selecting the subjects having both parents from a Gujarati background.

Cephalometric analysis performed manually using a tracing sheet on the radiograph is the oldest and the most widely used method. Digital imaging offers several advantages over conventional film based radiography such as faster data processing, elimination of chemicals and associated environmental hazards and the ability to alter and improve the image to correct for exposure errors, thus virtually eliminating the need for a second exposure. Digital radiographic images are easy to 
store and also facilitate communication. They also require lower levels of radiation. ${ }^{39,40}$ Hence, digital lateral cephalographs were chosen over manual ones for this study.

Computerized cephalometric analysis may use either a manual or automatic identification of landmarks. Automated systems at present are unable to compete with manual identification in terms of accuracy of landmark position. While different reference planes may be constructed to assist in identifying points like $\mathrm{Co}$, Gn during hand tracing, this may not be possible with on screen digitization. ${ }^{39}$ Hence, a manual tracing method was chosen to evaluate the printed radiographs.

McNamara suggested that a need has arisen for a method of cephalometric analysis that is sensitive not only to the position of the teeth within a given bone but also to the relationship of the jaw elements and cranial base structures one to another. He devised his method of analysis with an effort to relate teeth to teeth, teeth to jaws, each jaw to the other, and the jaws to the cranial base. ${ }^{41}$ This approach makes the actual analysis most suitable for diagnosis, treatment planning, and treatment evaluation. ${ }^{15}$ Further, this analysis uses linear measurements so that the treatment planning and diagnosis can be made easier. ${ }^{28}$ Also, no norms based on McNamara's analysis are available for the Gujarati population. Hence, this analysis was adopted for the current study.

\section{Gender Differences}

According to the present study, the gender wise differences in the measurements of the parameters of McNamara's analysis were statistically non-significant except for lower facial height (ANS $\mathrm{Me}$ ) measurement which revealed a statistically significant difference and was larger in male compared to female subjects. This finding was in accordance with the findings of sample of McNamara (1984) ${ }^{26}$ for Caucasian subjects. However, for sample of Chinese subjects of John Wu et al (2007), ${ }^{15}$ there were no statistically significant gender differences for the variables relating the maxilla to cranial base and dentition, but five of the six variables related to the mandible and maxilla, and the variable related to mandible to cranial base, showed statistically significant differences.

\section{Conclusion}

1) A total of 1500 children ( 750 boys and 750 girls) between the age group of 9 - 15 years from primary government funded schools in Ahmedabad and Gandhinagar district were included in the study.

2) This study introduces cephalometric norms for the mixed dentition period using McNamara Analysis for Gujarati children residing in Ahmedabad - Gandhinagar districts of Gujarat which are non-existent till date; and hence, can be utilized for better and accurate orthodontic treatments for this population group.

3) The normal values derived by the study are as follows:

4) Maxilla to cranial base relation:

- Mean $\mathrm{Na}-\mathrm{P}$ (Nasion perpendicular to point $\mathrm{A}$ ) value for boys was $-0.569 \mathrm{~mm}$ and 0.182 $\mathrm{mm}$ for girls.

- Mean SNA (Sella nasion angle) value for boys was 84.784 degrees and 84.259 degrees for girls.

5) Mandible to cranial base: 
- Mean Pog - NP (Pogonion to nasion perpendicular) value for boys was $-5.667 \mathrm{~mm}$ and $4.892 \mathrm{~mm}$ for girls.

6) Mandible to maxilla:

- Mean Co - Gn (Effective mandibular length) value for boys was $94.678 \mathrm{~mm}$ and 93.435 $\mathrm{mm}$ for girls.

- Mean Co - A (Effective midface length) value for boys was $78.908 \mathrm{~mm}$ and $77.432 \mathrm{~mm}$ for girls.

- Mean Mx - MD - DF (Maxillo mandibular differences) value for boys was $21.453 \mathrm{~mm}$ and $20.632 \mathrm{~mm}$ for girls.

- $\quad$ Mean ANS - Me (lower anterior face height) value for boys was $55.897 \mathrm{~mm}$ and 54.409 $\mathrm{mm}$ for girls.

- Mean MD - P (mandibular plane angle) value for boys was 24.832 degrees and 24.398 degrees for girls.

- Mean FA - Axis (facial axis angle) value for boys was 2.459 degrees and 2.702 degrees for girls.

7) Dentition:

- Mean Ui - A (upper incisor to point A) value for boys was $3.564 \mathrm{~mm}$ and $4.290 \mathrm{~mm}$ for girls.

- Mean Li - A - Pog (lower incisor to A - Pog line) value for boys was $3.334 \mathrm{~mm}$ and 3.025 $\mathrm{mm}$ for girls.

8) The gender related differences of the cephalometric parameters were insignificant for all except lower anterior facial height which was larger in Gujarati boys as compared to girls.

\section{References}

[1] Avesh S, Adit S, Chaturvedi T. Soft tissue cephalometric norms in a north Indian ethnic population. J Orthod Sci 2012;1(4):92-7.

[2] Tripti T, Rohit K, Kiran S, Rana M, Geeta V, Mayank A. Arnett's soft tissue cephalometric analysis norms for the North Indian population: A cephalometric study. J Ind Orthod Soc 2014;48(4):22432.

[3] Isha A, Anil S. Soft tissue cephalometric analysis applied to Himachali ethnic population. Indian J Dent Sci 2016;8:124-30.

[4] Manan A, Sonali D, Jayesh R, Vijay S, Charudatt N, Milind D. Mean values of Steiner, Tweed, Ricketts and McNamara analysis in Maratha ethnic population: A cephalometric study. APOS Trend Orthod 2013;3(5):137-51.

[5] Hung Huey Tsai. A study of growth changes in the mandible from deciduous to permanent dentition. J Clin Pediatr Dent 2003;27(2):137-42.

[6] Tollaro I, Baccetti T, Franchi L. Floating norms for the assessment of craniofacial pattern in the deciduous dentition. Eur J Orthod 1996;18:359-65.

[7] Magnani M, Nouer D, Kuramae M, Lucato A, Boeck M, Vedovello S. Evaluation of facial pattern in Black Brazilian subjects. Braz J Oral Sci 2007;6(23):1428-31.

[8] Kuramae M, Magnani M, Boeck E, Lucato A. Jarabak's cephalometric analysis of Brazilian black patients. Braz Dent J 2007;18(3):258-62.

[9] Nivedita S, Rajat M, Pritam M, Tushar N, Smruti N, Anand G. Cephalometric norms for east Indian population using Burstone Legan analysis. J Int Oral Health 2016;8(12):1076-81.

[10] Thilander B, Persson M, Adolfsson U. Roentgeno-cephalometric standards for a Swedish population: A longitudinal study between the ages of 5 and 31 years. Eur J Orthod 2005;27:37089. 
[11] Carrillo LE, Kubodera IT, Gonzalez LB, Bastida MN, Pereyra EG. Cephalometric norms according to the Harvold's analysis. Int J Odontostomat 2009;3(1):33-9.

[12] Yadav A, Singh C, Borle R, Chaoji K, Rajan R, Datarkar A. Cephalometric norms for Central Indian population using Burstone and Legan analysis. Indian J Dent Res 2011;22(1):27-33.

[13] Lalitha C, Anupriya J, Vasumurthy S, Sri Harsha Y. Evaluation of composite cephalometric norms in South Indian subjects. Orthod J Nepal 2015;5(2):25-7.

[14] Eldaissy AM. Cephalometric norms of Libyan children in mixed dentition phase. Cairo Dent J 2008;24(3):531-5.

[15] Wu J, Hagg U, Rabie BM. Chinese Norms of McNamara's Cephalometric Analysis. Angle Orthod 2007;77(1):12-20.

[16] Sahar F, Nabeel F. Cephalometric norms for Saudi sample using McNamara analysis. Saudi Dent J 2007;19(3):139-45.

[17] Hamdan AM, Rock WP. Cephalometric norms in an Arabic population. J Orthod 2001;28:297-300.

[18] Nanda R, Nanda R. Cephalometric study of the dentofacial complex of North Indians. Angle Orthod 1969;39(1):22-8.

[19] Satinder S, Ashok U, Ashok J. Cephalometric norms for orthognathic surgery for North Indian population. Contemporary Clin Dent 2013;4(4):460-6.

[20] Tweed CH. The Frankfort-mandibular incisor angle (FMIA) in orthodontic diagnosis, treatment planning and prognosis. Angle Orthod 1954;24:121-69.

[21] Steiner CC. The use of cephalometrics as an aid to planning and assessing orthodontic treatment. Am J Orthod Dentofacial Orthop 1960;46:721-35.

[22] Ricketts RM. Cephalometric analysis and synthesis. Angle Orthod 1961;31:141-56.

[23] Bjork A. The face in profile. Svensk Tandlakare Tidskrift; 40, No. 5B, 1947.

[24] Downs WB. Variations in facial relationships: their significance in treatment and prognosis. Am J Orthod Dentofacial Orthop 1948;34:812-40.

[25] Enlow DH, Kuroda T, Lewis AB. The morphological and morphogenetic basis for craniofacial form and pattern. Angle Orthod 1971;41:161-88.

[26] McNamara JA. A method of cephalometric evaluation. Am J Orthod Dentofacial Orthop 1984;86:449-69.

[27] Obloj B, Fudalej P, Dudkiewicz Z. Cephalometric Standards for Polish 10 Year Olds with Normal Occlusion. Angle Orthod 2008;78(2):262-9.

[28] Bhat M, Sudha P, Tandon S. Cephalometric norms for Bunt and Brahmin children of Dakshina Kannada based on McNamara's analysis. J Indian Soc Pedod Prev Dent 2001;19(2):41-51.

[29] Silva C, Pinhao AF. Frankfort plane vs. natural head posture in cephalometric diagnosis. Dent Med Probl 2003;40(1):129-134.

[30] Hassan AH. Cephalometric norms for the Saudi children living in the western region of Saudi Arabia: a research report. Head Face Med 2005;1(5):6-12.

[31] Arunkumar KV, Vardhan V, Tauro DP. Establishment of cephalometric norms for the South Indian population based on Burstone's analysis. J Oral Maxillofac Surg 2010;9(2):127-33.

[32] Wu J, Hagg U, Wong R, McGrath C. Comprehensive cephalometric analyses of 10 to 14 year old Southern Chinese. Open Anthropol J 2010;3:85-95.

[33] Dreven M, Farcnik F, Vidmar G. Cephalometric standards for Slovenians in the mixed dentition period. Eur J Orthod 2006;28:51-7.

[34] Kotak VB. Cephalometric evaluation of Indian girls with neutral occlusion. J Indian Dent Assoc 1964;36:183.

[35] Johannsdottir B, Thordarson A, Magnusson T. Craniofacial morphology in 6 year old Icelandic children. Eur J Orthod 1999;21:283-90.

[36] Kalha AS, Latif A, Govardhan SN. Soft-tissue cephalometric norms in a South Indian ethnic population. Am J Orthod Dentofacial Orthop 2008;133(6):876-81.

[37] Abu HM, Alshamsi AH, Hafez S, Eldin EM. Cephalometric norms for a sample of Emirates adults. Open J Stomatol 2011;1:75-83. 
[38] Dean J, Avery D, McDonald R. Dentistry for the child and adolescent. 9th ed. Mosby: Reed Elsevier India Pvt. Ltd; 2011.

[39] Agarwal N, Bagga D, Sharma P. A comparative study of cephalometric measurements with digital versus manual methods. J Ind Orthod Soc 2011;45(2):84-90.

[40] White SC, Pharoah MJ. Oral Radiology: Principles \& Interpretation. 6th ed. Noida: Reed Elsevier India Private Limited; 2009.

[41] Nahidh M. Iraqi cephalometric norms using McNamara's analysis. J Bagh Col Dent 2010;22(3):123-7. 